\title{
Sensorless Fault-Tolerant Control of an Induction Motor Based Electric Vehicle
}

\author{
Toufik Roubache ${ }^{\dagger}$, Souad Chaouch* and Med Said Nait Said*
}

\begin{abstract}
This paper describes a sensorless fault-tolerant control (FTC) for a high-performance induction motor drive that propels an electric-vehicle (EV). The effect of the fault on the induction motor (IM) can be modeled by an exogenous signal from a stable autonomous system. An additive term is added to the nominal offset and serves to control the effect of the defect (FTC aspect). The proposed sensorless FTC for IM is realized in presence of both rotor and stator electrical faults. Consequently, the extended kalman filter (EKF) is proposed to estimate the rotor flux and the rotor speed using the measured stator currents and voltages. Therefore, a classical EV traction system is studied using an induction motor drive. Indeed, the induction motor based powertrain is coupled to DC machine-based load torque emulator taking into account the electric vehicle mechanics and aerodynamics. Simulation and experimental results confirm widely the feasibility and the effectiveness of the proposed FTC of IM based SMC in the electric vehicle application.
\end{abstract}

Keywords: Fault-Tolerant Control (FTC), Induction Motor (IM), Sliding Mode Control (SMC), Internal Model, Extended Kalman Filter (EKF), Electric Vehicle (EV).

\section{Introduction}

Recently, fault-tolerant control (FTC) has begun to concern a wider range of industrial applications such as aerospace, automotive, nuclear power, manufacturing, etc. The past two decades have therefore seen considerable research on Fault Tolerant Control (FTC). FTC systems are designed to allow recovery from damage and system faults. When it comes to electrical drives used in safety critical applications or industrial processes where system faults may lead to enormous costs, FTC systems are crucial [1]. Stator, rotor and shaft faults together constitute up to $47 \%$ of recorded induction motor faults [1,2]. Specifically, we address the case in which the faults affecting the controlled system can be modeled as functions (of time) within a finitely parameterized family.

Then, we design a controller, which embeds an internal model of this family, whose purpose is to generate supplementary control actions which compensate for the presence of any of such faults, regardless their entity.

In other words, the control reconfiguration does not rely upon an explicit FDI (Fault Detection and Isolation) design but, indeed, is achieved by a proper design of a dynamic controller, which is implicitly fault tolerant to all the possible faults whose model is embedded in the regulator. To increase the reliability and the continuous operation of electromechanical systems interest in fault tolerance has

$\dagger$ Corresponding Author: Dep. of Electrical engineering, University of M'sila, Algeria. (toufik.roubache@gmail.com)

* Laboratory of electromagnetic induction and propulsion systems, Dep of Electrical engineering, University of Batna, Algeria. ( $\{$ Chaouchsouad, medsnaitsaid\}@yahoo.fr)

Received: August 27, 2014; Accepted: March 1, 2016 grown $[3,4]$. Indeed, extensive research has been conducted toward fault-tolerant alternating-current motor drives in industrial applications $[5,6]$. Fault tolerance is no longer limited to high-end systems but also to railway [7], and automobile applications. It becomes an important means to increase the reliability, availability, and continuous operation of electromechanical systems among the automotive ones [8]. Since the early 1990s there has been resurgence in electric vehicles (EVs) research, stimulated by various factors such as rising oil prices, environmental concerns, cost reduction of power electronics and motor drives, and a marked improvement in energy storage technologies [9]. Electric vehicles (EVs) have become very attractive in replacing conventional internal combustion engine vehicles because of environmental and energy issues. They have received a great attention from the research community. Control methodologies have been actively developed and applied to EVs to improve the EVs performances [10,11]. A classical EV traction system is studied using an induction motor drive. A separated excited DC load is thus controlled to impose the same behavior of the mechanical power train to the induction motor.

However, this control needs accurate information about rotor speed. The extended kalman filter (EKF) has been successfully applied for sensorless control of induction motor. Consequently, it is considered to be the best solution for the speed and flux estimation using the stator currents and stator voltages of the induction motor drive [12-13].

This paper is organized as follows. In Section 2, the nonlinear model of IM in presence of faults and dynamic of EV are presented. The sensorless sliding mode control (SMC) for the IM is designed in Section 3. The proposed 
fault tolerant control strategy is described in Section 4. Section 5 is devoted to the presentation of the simulation results obtained for various fault-free situations and fault scenarios when the proposed scheme is applied to the IM. Section 6 presents the experimental results, which shows the effectiveness of the proposed control scheme. Finally, conclusion is provided in Section 7.

\section{Modeling of the Traction System}

\subsection{Induction motor model in presence of faults}

The induction motor state model developed in the stationary reference frame in presence of faults is given by:

$$
\dot{x}=f(x)+B u+\gamma V_{f}
$$

with:

$$
\begin{aligned}
& \left\{\begin{array}{l}
\gamma=\left[\begin{array}{llll}
1 & 0 & 0 & 0 \\
0 & 1 & 0 & 0
\end{array}\right]^{T} \\
V_{f}=\left[\begin{array}{lll}
V_{f 1} & V_{f 2}
\end{array}\right]^{T}
\end{array}\right.
\end{aligned}
$$

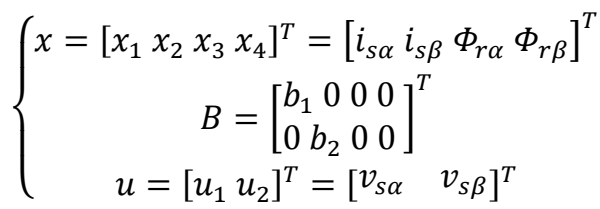

where:

$$
\left\{\begin{array}{c}
\dot{x}_{1}=a_{1} x_{1}+a_{2} x_{3}+a_{3} x_{4} \omega_{r}+b_{1} u_{1} \\
\dot{x}_{2}=a_{1} x_{2}-a_{3} x_{3} \omega_{r}+a_{2} x_{4}+b_{2} u_{2} \\
\dot{x}_{3}=a_{4} x_{1}+a_{5} x_{3}-x_{4} \omega_{r} \\
\dot{x}_{4}=a_{4} x_{2}+x_{3} \omega_{r}+a_{5} x_{4}
\end{array}\right.
$$

with:

$$
\left\{\begin{array}{c}
a_{1}=-\left(\frac{R_{s}}{\sigma L_{s}}+\frac{1-\sigma}{\sigma T_{r}}\right), a_{2}=\frac{1-\sigma}{M \sigma T_{r}}, a_{3}=\frac{M}{\sigma L_{s} L_{r}} \\
a_{4}=\frac{M}{T_{r}}, a_{5}=-\frac{1}{T_{r}}, a_{6}=\frac{M}{T_{r}}, a_{7}=\frac{M}{J L_{r}}, a_{8}=\frac{T_{L}}{J} \\
b_{1}=b_{2}=\frac{1}{\sigma L_{s}}
\end{array}\right.
$$

$\sigma$ is the coefficient of dispersion, $L_{s}, L_{r}, M$ are stator, rotor and mutual inductance, respectively. $R_{s}, R_{r}$ are respectively stator and rotor resistance. $T_{r}$ is the rotor time constant $\left(T_{r}=\frac{L_{r}}{R_{r}}\right)$.

The presence of electrical faults generates asymmetry of the IM yielding some slot harmonics in the stator winding. In the two-phase model, it is possible to model this effect thinking of a sinusoidal component, which corrupts the stator currents, i.e:

$$
\sum_{i}^{n_{f}} A_{i} \sin \left(\omega_{i} t+\varphi_{i}\right) \text { and } \sum_{i}^{n_{f}} A_{i} \cos \left(\omega_{i} t+\varphi_{i}\right)
$$

These assumptions allow us to express the deviation of the stator currents values in presence of faults values as [14]:

$$
\left\{\begin{array}{c}
i_{\alpha} \rightarrow i_{\alpha}+\sum_{i}^{n_{f}} A_{i} \sin \left(\omega_{i} t+\varphi_{i}\right) \\
i_{\beta} \rightarrow i_{\beta}+\sum_{i}^{n_{f}} A_{i} \cos \left(\omega_{i} t+\varphi_{i}\right) \\
i=1, \ldots, n_{f}
\end{array}\right.
$$

with:

$n_{f}:$ faults number,

$$
\omega_{i}=2 \pi f_{i}+2 \pi f_{a}=2 \pi \cdot\left(f_{i}+f_{a}\right)
$$

where:

$f_{i}$ is the characteristic frequency of the fault and $f_{a}$ is the fundamental frequency.

The frequency dependent on the kind of fault, which belongs to the two possible classes (rotor or stator faults), and unknown amplitude and phase. The latter depending on the fault severity. In particular it is easy to realize that, defining the exosystem:

$$
\dot{Z}=S_{f} Z
$$

with:

$$
\left\{\begin{aligned}
S_{f} & =\operatorname{diag}\left(S_{f i}\right) \\
S_{f i} & =\left[\begin{array}{cc}
0 & \omega_{i} \\
-\omega_{i} & 0
\end{array}\right] \\
Z & =\left[\begin{array}{c}
Z_{2 i-1} \\
Z_{2 i}
\end{array}\right] \\
i & =1, \ldots, n_{f}
\end{aligned}\right.
$$

The additive perturbing terms in (7) can be thought as a suitable combination of the exosystem state, namely:

$$
\begin{aligned}
& i_{\alpha} \rightarrow i_{\alpha}+Q_{d} Z \\
& i_{\beta} \rightarrow i_{\beta}+Q_{q} Z
\end{aligned}
$$

with:

$$
\begin{aligned}
& \left\{Q_{d}=\left[\begin{array}{lllllll}
1 & 0 & 1 & 0 & \ldots & 1 & 0
\end{array}\right]\right. \\
& \left\{Q_{q}=\left[\begin{array}{lllllll}
0 & 1 & 0 & 1 \ldots & 0 & 1
\end{array}\right]\right.
\end{aligned}
$$

In this way, the uncertainty on the amplitude and phase of the additive sinusoidal terms in the faulty condition

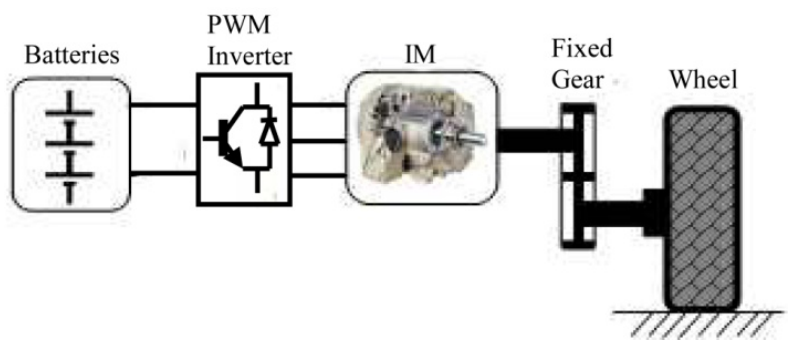

Fig. 1. Traction system scheme of the EV 
reflects in that on the initial state of the exosystem. In view of this, it is readily seen that the model of the IM in presence of faults is given by (1) with the exogenous input $V_{f}$ equal to:

$$
\begin{gathered}
V_{f}=\left[\begin{array}{l}
V_{f 1} \\
V_{f 2}
\end{array}\right]=-\left[\begin{array}{l}
a_{1} Q_{d} Z+Q_{d} S_{f} Z \\
a_{1} Q_{q} Z+Q_{q} S_{f} Z
\end{array}\right] \\
\left\{\begin{array}{c}
V_{f}=-\left[\begin{array}{l}
a_{1} Q_{d}+Q_{d} S_{f} \\
a_{1} Q_{q}+Q_{q} S_{f}
\end{array}\right] Z=-\Gamma Z \\
\text { where }:
\end{array}\right. \\
\Gamma=\left[\begin{array}{l}
\Gamma_{1} \\
\Gamma_{2}
\end{array}\right]=\left[\begin{array}{l}
{\left[a_{1} Q_{d}+Q_{d} S_{f}\right.} \\
{\left[a_{1} Q_{q}+Q_{q} S_{f}\right.}
\end{array}\right]
\end{gathered}
$$

\subsection{Modeling and dynamics of the EV load torque emulator}

The EV model and the contact law between wheel and road may be taken into account for a dynamic modeling. But the slip phenomenon is complex and requires specific controllers for good dynamic performance [15].

The road load is then given by [16]:

$$
F_{w}=F_{a d}+F_{r o}+F_{p r}+F_{s f}
$$

with $F_{a d}$ is the aerodynamic drag force, $F_{r o}$ is the rol ling resistance force, $F_{p r}$ is the profile force of the roa $\mathrm{d}$, and $F_{s f}$ is the Stokes or viscous friction force.

The vehicle velocity $v_{e v}$ is obtained using the classical dynamics relationship with the traction and road load forces, $F_{t}$ and $F_{w}[17]$ :

$$
M_{e v} \frac{d v_{e v}}{d t}=F_{t}-F_{w}
$$

with $M_{e v}$ the mass of the vehicle.

The mechanical equation used to describe each wheel drive is expressed by:

$$
J_{t m} \frac{d \omega_{m}}{d t}=T_{m}-T_{B}-T_{L}
$$

where $J_{t m}$ is the moment of inertia, $T_{m}$ is the motor $\mathrm{t}$ orque, $T_{B}$ is the load torque accounting for friction an d windage, and $T_{L}$ is the load torque.

The gearbox leads to the gearbox torque $T_{W}$ and the rotation speed $\omega_{W}$ respectively is given by:

$$
\left\{\begin{array}{c}
T_{W}=N \eta_{t r} T_{m} \\
\omega_{W}=\frac{w_{m}}{N}
\end{array}\right.
$$

The load torque in the motor referential is then given by:

$$
T_{L}=\frac{T_{L W}}{N}=\frac{R_{W} F_{W}}{N}
$$

where $N$ is the transmission ratio, $\eta_{t r}$ is the transmissi on efficiency, and $R_{W}$ is the wheel radius.

\section{Sensorless Sliding Mode Control}

\subsection{Sliding mode control of IM}

Sliding Mode Control is considered to be the appropriate methodology for the robust nonlinear control of induction motor drives due to its order reduction, disturbance rejection, strong robustness and simple implementation by means of power converter [18]. The surfaces proposed by J.J.Slotine are given by:

$$
\begin{aligned}
& S_{1}\left(\omega_{r}\right)=k_{1}\left(\omega_{r}-\omega_{r e f}\right)+\left(\dot{\omega}_{r}-\dot{\omega}_{r e f}\right) \\
& S_{2}\left(\Phi_{r}\right)=k_{2}\left(\Phi_{r}-\Phi_{r e f}\right)+\left(\dot{\Phi}_{r}-\dot{\Phi}_{r e f}\right)
\end{aligned}
$$

with $k_{1}$ and $k_{2}$ are positive gains.

The corresponding derivative are:

$$
\begin{aligned}
& \dot{S}_{1}\left(\omega_{r}\right)=k_{1}\left(\dot{\omega}_{r}-\dot{\omega}_{r e f}\right)+\left(\ddot{\omega}_{r}-\ddot{\omega}_{r e f}\right) \\
& \dot{S}_{2}\left(\Phi_{r}\right)=k_{2}\left(\dot{\Phi}_{r}-\dot{\Phi}_{r e f}\right)+\left(\ddot{\Phi}_{r}-\ddot{\Phi}_{r e f}\right)
\end{aligned}
$$

After simplification calculates derivatives of the sliding surfaces are given in matrix form as follows:

$$
\left[\begin{array}{c}
\dot{S}_{1} \\
\dot{S}_{2}
\end{array}\right]=\left[\begin{array}{l}
F_{1} \\
F_{2}
\end{array}\right]+\left[\begin{array}{cc}
-b_{2} \Phi_{r \beta} & b_{1} \Phi_{r \alpha} \\
b_{1} M \Phi_{r \alpha} & b_{2} M \Phi_{r \beta}
\end{array}\right]\left[\begin{array}{c}
V_{s \alpha} \\
V_{s \beta}
\end{array}\right]
$$

with:

$$
\begin{aligned}
& F_{1}=\left(k_{1}-a_{5}-\right.\left.a_{1}\right) a_{7}\left(i_{s \beta} \Phi_{r \alpha}-i_{s \alpha} \Phi_{r \beta}\right)-k_{1} a_{8} \\
&-\omega_{r} a_{7}\left(i_{s \alpha} \Phi_{r \alpha}+i_{s \beta} \Phi_{r \beta}+a_{3} \Phi_{r}\right) \\
&-k_{1} \dot{\omega}_{r e f}-\ddot{\omega}_{r e f} \\
& F_{2}=2 a_{5}\left(\frac{2+M \sigma}{T_{r}}-k_{2}\right) \Phi_{r} \\
&+2 a_{4}\left(\frac{M}{T_{r}}\left(i_{s \alpha}{ }^{2}+i_{s \beta}{ }^{2}\right)\right. \\
&+\left(k_{2}-\frac{3}{T_{r}}-a_{1}\right)\left(i_{s \alpha} \Phi_{r \alpha}+i_{s \beta} \Phi_{r \beta}\right) \\
&\left.+p \omega_{r}\left(i_{s \beta} \Phi_{r \alpha}-i_{s \alpha} \Phi_{r \beta}\right)\right)-k_{2} \dot{\Phi}_{r e f} \\
&-\ddot{\Phi}_{r e f}
\end{aligned}
$$

The condensed form of (24) is given by:

$$
\dot{S}=F+D V_{s \alpha \beta}
$$

And check the condition of Lyapunov stability $\left(S_{i} \dot{S}_{i}<0\right)$, must have:

$$
\dot{S}=-v \operatorname{sign}(S)
$$

Equating (25) and (26) we have:

$$
V_{s \alpha \beta}=-D^{-1} v \operatorname{sign}(S)-D^{-1} F
$$

The law equivalent control is given by: 


$$
\left[\begin{array}{l}
V_{e q \alpha} \\
V_{e q \beta}
\end{array}\right]=-D^{-1}\left[\begin{array}{l}
F_{1} \\
F_{2}
\end{array}\right]
$$

The law of attractive control is given by:

$$
\left[\begin{array}{l}
V_{c \alpha} \\
V_{c \beta}
\end{array}\right]=-D^{-1}\left[\begin{array}{cc}
v_{1} & 0 \\
0 & v_{2}
\end{array}\right]\left[\begin{array}{l}
\operatorname{sign}\left(S_{1}\right) \\
\operatorname{sign}\left(S_{2}\right)
\end{array}\right]
$$

where: $v_{1}>\left|F_{1}\right|, v_{1}>\left|F_{2}\right|$

Selecting the gain $\mathrm{k}_{\mathrm{i}}$ is such that the desired value is imposed at the output of each regulator. The global control ensuring both $\left(S_{i}=0\right.$ and $\left.S_{i} \dot{S}_{i}<0\right)$ is given by:

$$
V_{s \alpha \beta}=\left[\begin{array}{c}
V_{s \alpha} \\
V_{s \beta}
\end{array}\right]=\left[\begin{array}{c}
V_{e q \alpha} \\
V_{e q \beta}
\end{array}\right]+\left[\begin{array}{c}
V_{c \alpha} \\
V_{c \beta}
\end{array}\right]
$$

\subsection{Speed observer}

In an induction motor drive, the Kalman filter is used to obtain unmeasured state variables (rotor speed $\omega_{r}$, rotor flux vector components $\Phi_{r \alpha}$ and $\left.\Phi_{r \beta}\right)$. The induction motor state model used by the EKF is developed in the stationary reference frame and summarized by:

$$
\frac{d}{d t}\left[\begin{array}{c}
i_{s \alpha} \\
i_{s \beta} \\
\Phi_{r \alpha} \\
\Phi_{r \beta} \\
\omega_{r}
\end{array}\right]=\left[\begin{array}{ccccc}
a_{1} & 0 & a_{2} & a_{3} \omega_{r} & 0 \\
0 & a_{1} & -a_{3} \omega_{r} & a_{2} & 0 \\
a_{4} & 0 & a_{5} & -\omega_{r} & 0 \\
0 & a_{4} & \omega_{r} & a_{5} & 0 \\
0 & 0 & 0 & 0 & 1
\end{array}\right]\left[\begin{array}{c}
i_{s \alpha} \\
i_{s \beta} \\
\Phi_{r \alpha} \\
\Phi_{r \beta} \\
\omega_{r}
\end{array}\right]+\left[\begin{array}{cc}
b_{1} & 0 \\
0 & b_{2} \\
0 & 0 \\
0 & 0 \\
0 & 0
\end{array}\right]\left[\begin{array}{c}
v_{s \alpha} \\
v_{s \beta}
\end{array}\right]
$$

The discrete induction motor state model used by the EKF is summarized by:

$$
\left\{\begin{array}{c}
x(k+1)=f(x(k), u(k))+w(k) \\
y(k+1)=h(x(k+1))+v(k)
\end{array}\right.
$$

where $w(k)$ represents the disturbances vector applied to the system inputs. It also represents modeling uncertainties; $v(k)$ corresponds to system output measurement noises. It is supposed that the random signals $v(k)$ and $w(k)$ are Gaussian noises not correlated and with null average value. They are characterized by covariance matrixes, $Q$ and $R$ respectively, which are symmetrical and positive definite. with:

$$
\left\{f=\left[\begin{array}{c}
\left(1-T_{e} a_{1}\right) i_{s \alpha}+T_{e} a_{2} \Phi_{r \alpha}+T_{e} a_{3} \omega_{r} \Phi_{r \beta}+T_{e} b_{1} v_{s \alpha} \\
\left(1-T_{e} a_{1}\right) i_{s \beta}-T_{e} a_{3} \omega_{r} \Phi_{r \alpha}+T_{e} a_{2} \Phi_{r \beta}+T_{e} b_{2} v_{s \beta} \\
T_{e} a_{4} i_{s \alpha}+\left(1-T_{e} a_{5}\right) \Phi_{r \alpha}-T_{e} \omega_{r} \Phi_{r \beta} \\
T_{e} a_{4} i_{s \beta}+T_{e} \omega_{r} \Phi_{r \alpha}+\left(1-T_{e} a_{5}\right) \Phi_{r \beta} \\
\omega_{r} \\
h=C x_{k \mid k+1}=\left[\begin{array}{ll}
i_{s \alpha} & i_{s \beta}
\end{array}\right]^{T}
\end{array}\right]\right.
$$

- Estimation of error covariance matrix

$$
P(k+1 \mid k)=F(k) P(k) F(k)^{T}+Q
$$

- Kalman filter gain

$K(k+1)=P(k+1 \mid k) C^{T}\left[C P(k+1 \mid k) C^{T}+R\right]^{-1}$

- Update of the error covariance matrix

$P(k+1 \mid k+1)=P(k+1 \mid k)\left[I_{n}-C K(k+1)\right]$

The speed adaptive mechanism is then given by [19]:

$\widehat{\omega}_{r}=K_{p}\left(e_{s \alpha} \widehat{\Phi}_{r \beta}-e_{s \beta} \widehat{\Phi}_{r \alpha}\right)+K_{i} \int\left(e_{s \alpha} \widehat{\Phi}_{r \beta}-e_{s \beta} \widehat{\Phi}_{r \alpha}\right) d t$

where: $e_{s \alpha}=i_{s \alpha}-\hat{i}_{s \alpha}$ and $e_{s \beta}=i_{s \beta}-\hat{i}_{s \beta}$.

$K_{p}, K_{i}$ are positive gains.

Thus, the speed value can be estimated by a simple PI controller, to minimize the error $\varepsilon$ defined by the following expression:

$$
\varepsilon=\left(e_{s \alpha} \widehat{\Phi}_{r \beta}-e_{s \beta} \widehat{\Phi}_{r \alpha}\right)
$$

\section{Fault-Tolerant and Load Drive Controller}

The fault scenario considered in this paper addresses electrical faults caused both by rotor and stator failures of the IM. Fig. (2) shows the proposed flexible architecture for fault tolerant control purposes that maintains maximum performance and the overall system failure rate at an acceptable level. The IM drive will be evaluated using a controlled load drive. This load drive has to impose the same rotation speed as imposed by the mechanical power train (Load characteristics of Electric Vehicle). To provide the right set point to the DC machine rotation speed, the mechanical model is used with the IM torque as input.

The objective of this technique is to provide an internal model that generates an additive term $u_{a d}$ zero in the absence of faults that are added to the nominal control to compensate the effect of faults on the system. The new

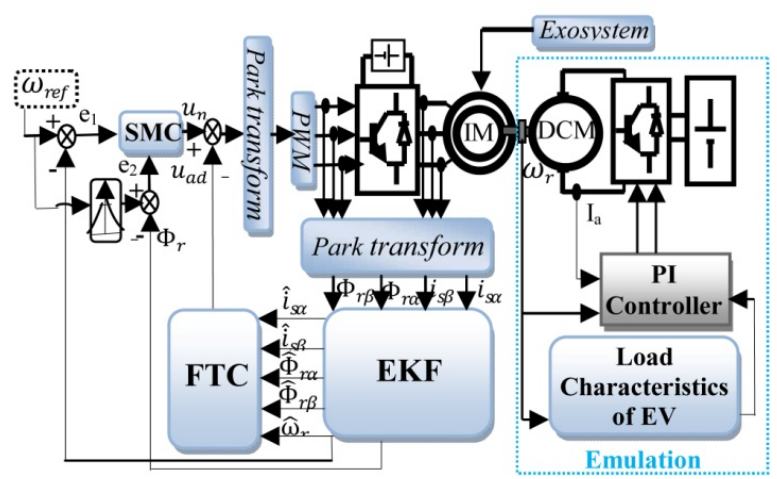

Fig. 2. The proposed fault tolerant control scheme 
control is then expressed by:

$$
u=\left[\begin{array}{l}
u_{1} \\
u_{2}
\end{array}\right]=\left[\begin{array}{l}
u_{1 \text { nom }} \\
u_{2 n o m}
\end{array}\right]+\left[\begin{array}{l}
u_{1 a d} \\
u_{2 a d}
\end{array}\right]+\left[\begin{array}{l}
u_{1 c} \\
u_{2 c}
\end{array}\right]
$$

The term is used to compensate $\left(u_{c}=\left[\begin{array}{l}u_{1 c} \\ u_{2 c}\end{array}\right]\right)$ known terms, which allows to give a suitable form to the system dynamics of the error, on the basis of which the unknown term $u_{a d}$ calculated [20]. The instantaneous difference between the derivative of the system state and the set value becomes:

$$
\dot{\bar{x}}=\left[\begin{array}{c}
\dot{\bar{x}}_{1} \\
\dot{\bar{x}}_{2} \\
\dot{\bar{x}}_{3} \\
\dot{\bar{x}}_{4}
\end{array}\right]-\left[\begin{array}{c}
\dot{x}_{1 r e f} \\
\dot{x}_{2 r e f} \\
\dot{x}_{3 r e f} \\
\dot{x}_{4 r e f}
\end{array}\right]=\left\{\begin{array}{c}
-\eta \bar{x}_{1}+b_{1} u_{1 a d}-V_{f 1} \\
-\eta \bar{x}_{2}+b_{2} u_{2 a d}-V_{f 2} \\
a_{6} \bar{x}_{1}+a_{5} \bar{x}_{3}-\dot{x}_{3 r e f} \\
a_{7} \bar{x}_{2} \bar{x}_{3}-\dot{x}_{4 r e f}
\end{array}\right.
$$

where:

$$
\left\{\begin{array}{c}
V_{f 1}=\Gamma_{1} Z_{1} \\
V_{f 2}=\Gamma_{2} Z_{2}, \eta=\frac{\left(M^{2} R_{r}+L_{r}{ }^{2} R_{s}\right)}{\left(\sigma L_{s} L_{r}{ }^{2}\right)}
\end{array}\right.
$$

For the determination of $u_{a d}$ we consider the following system:

$$
\tilde{x}=\left[\begin{array}{l}
\bar{x}_{1} \\
\bar{x}_{2}
\end{array}\right]
$$

Whose dynamics is derived from the system (39):

$$
\left\{\begin{array}{c}
\dot{Z}=S_{f} Z \\
\dot{\tilde{x}}=\left[\begin{array}{c}
\dot{\bar{x}}_{1} \\
\dot{\bar{x}}_{2}
\end{array}\right]=\left[\begin{array}{l}
-\eta \bar{x}_{1}+b_{1} u_{1 a d}-\Gamma_{1} Z_{1} \\
-\eta \bar{x}_{2}+b_{2} u_{2 a d}-\Gamma_{2} Z_{2}
\end{array}\right]
\end{array}\right.
$$

The Eq. (41) can be written in matrix form:

$$
\dot{\tilde{x}}=H(\tilde{x})+\tilde{B} u_{a d}-\Gamma Z
$$

with:

$$
\left\{\begin{array}{c}
H(\tilde{x})=\tilde{A} \tilde{x} \\
\tilde{A}=\left[\begin{array}{cc}
-\eta & 0 \\
0 & -\eta
\end{array}\right] \\
\tilde{B}=\left[\begin{array}{ll}
b_{1} & 0 \\
0 & b_{2}
\end{array}\right]
\end{array}\right.
$$

\subsection{Internal model}

Assuming that the characteristics of $\omega_{i}$ faults (number $n_{f}$ and thus the matrices $S_{f}$ and $\Gamma$ pulses) are perfectly known, consider the following Sylvester equation [21]:

$$
M_{s} S_{f}-F M_{s}=G \Gamma
$$

$F$ and $G$ are matrices of suitable dimensions such that
$F$ is an arbitrary stable (Hurwitz), and $G$ selected such that the pair $(F, G)$ is available:

$$
\left\{\begin{array}{l}
\operatorname{dim}(F)=2 n_{f} \times 2 n_{f} \\
\operatorname{dim}(G)=2 n_{f} \times 2
\end{array}\right.
$$

$M_{S}$ is the unique solution of the Sylvester equation and is non-singular. The internal model takes the following form (known $S_{f}$ ):

$$
\left\{\begin{array}{c}
\dot{\xi}=S_{f} \xi+N(\tilde{x}) \\
\operatorname{dim}(\xi)=\operatorname{dim}(Z)=2 n_{f}
\end{array}\right.
$$

Consider the system (40), $u_{a d}$ is selected so as to:

$$
u_{a d}=\tilde{B}^{-1} \Gamma \xi
$$

And the expression (42) of $\dot{\tilde{x}}$ becomes:

$$
\left\{\begin{array}{c}
\dot{\tilde{x}}=H(\tilde{x})+\Gamma(\xi-Z) \\
\dot{\tilde{x}}=\tilde{A} \tilde{x}+\Gamma e
\end{array}\right.
$$

The new error variable is considered:

$$
e=(\xi-Z)
$$

We derive with respect to time, taking into account the dynamics of the internal model and the faults:

$$
\left\{\begin{array}{c}
\dot{e}=(\dot{\xi}-\dot{Z})=S_{f} \xi+N(\tilde{x})-S_{f} Z \\
\dot{e}=S_{f} e+N(\tilde{x})
\end{array}\right.
$$

The equations describing the dynamics of closed-loop errors are:

$$
\left\{\begin{array}{c}
\dot{\tilde{x}}=\tilde{A} \tilde{x}+\Gamma e \\
\dot{e}=S_{f} e+N(\tilde{x})
\end{array}\right.
$$

We need to find the expression of $N(\tilde{x})$ which cancels the error of observation of faults and allows at the same time to reject their effect because it also cancels $\tilde{x}$. Is the Lyapunov function of (51), we have:

$$
V=\frac{1}{2} \tilde{x}^{T} \tilde{x}+\frac{1}{2} e^{T} e
$$

After development and derivative with respect to time, $\dot{V}$ becomes:

$$
\dot{V}=\tilde{x}^{T} \tilde{A} \tilde{x}+e^{T} \Gamma^{T} \tilde{x}+e^{T} N(\tilde{x})
$$

Finally $\dot{V}$ is written as following:

$$
\dot{V}=\tilde{x}^{T} \tilde{A} \tilde{x} \leq 0
$$


In this case the choice of $N(\tilde{x})$ is given by:

$$
N(\tilde{x})=-\Gamma^{T} \tilde{x}
$$

Then the system (51) becomes:

$$
\left\{\begin{array}{l}
\Gamma e=0 \\
\dot{e}=s_{f} e
\end{array}\right.
$$

Finally the objective of the control is achieved by adopting the procedure performed and may compensate for the effect of faults on the system $(\bar{x} \rightarrow 0)$ and replicate $(e \rightarrow 0)$ in the internal model. $(\bar{x} \rightarrow 0)$ and reproduce $(e \rightarrow 0)$ in the internal model.

\section{Simulation Results}

In order to evaluate the proposed fault-tolerant sliding control strategy performance, simulations have been carried-out for an electric vehicle using a $1 \mathrm{~kW}$ induction motor with squirrel cage rotor based powertrain, supplied by a 3-leg VSI and a $1 \mathrm{~kW}$ separated excited DC machine supplied by a 4-quadrant chopper. The model of EV consists of a mass of $1.5 \mathrm{t}$, a wheel radius of $0.3 \mathrm{~m}$, and a
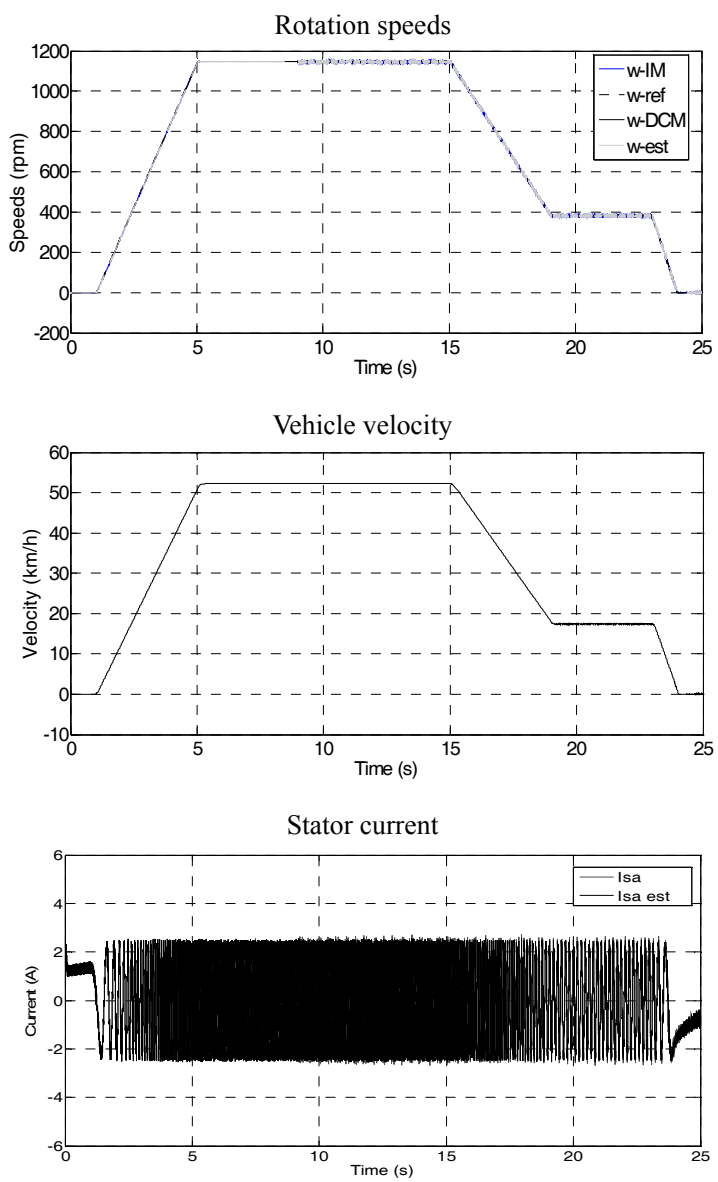

Fig. 3. One fault affects the motor in the stator vehicle width of $1.6 \mathrm{~m}$. The adaptation coefficients are chosen in function of speed and torque limitations: $N=20$. The nominal parameters values of the studied induction motor and separated excited DC machine are shown in appendix.

\subsection{Simulation of the sliding mode control}

Figs. 3 and 4 illustrate the simulation models developed for the performance of the SMC. Firstly, no- perturbations, then at $\mathrm{t}=8 \mathrm{sec}$, introducing perturbations in the parameters $80 \%$ in rotor resistance $\left(R_{r}\right)$ and stator resistance $\left(R_{s}\right)$, after at $\mathrm{t}=9 \mathrm{sec}$ occurrence of a single fault in the stator. A trapezoidal trajectory with a reverse operation is imposed as set point of the vehicle velocity $v_{\text {ev ref }}$. The rotation speed of the machine is closed to the speed generated by the mechanical model.

Then, two faults are introduced at $\mathrm{t}=9 \mathrm{sec}$, one in the stator and the other in the rotor.

From these results, we can see that the proposed control is robust to parameter perturbations and load torque, but is insufficient in case of faults. Increased strength reduces the error on the speed and flux but does not negate the effect of faults on the currents.
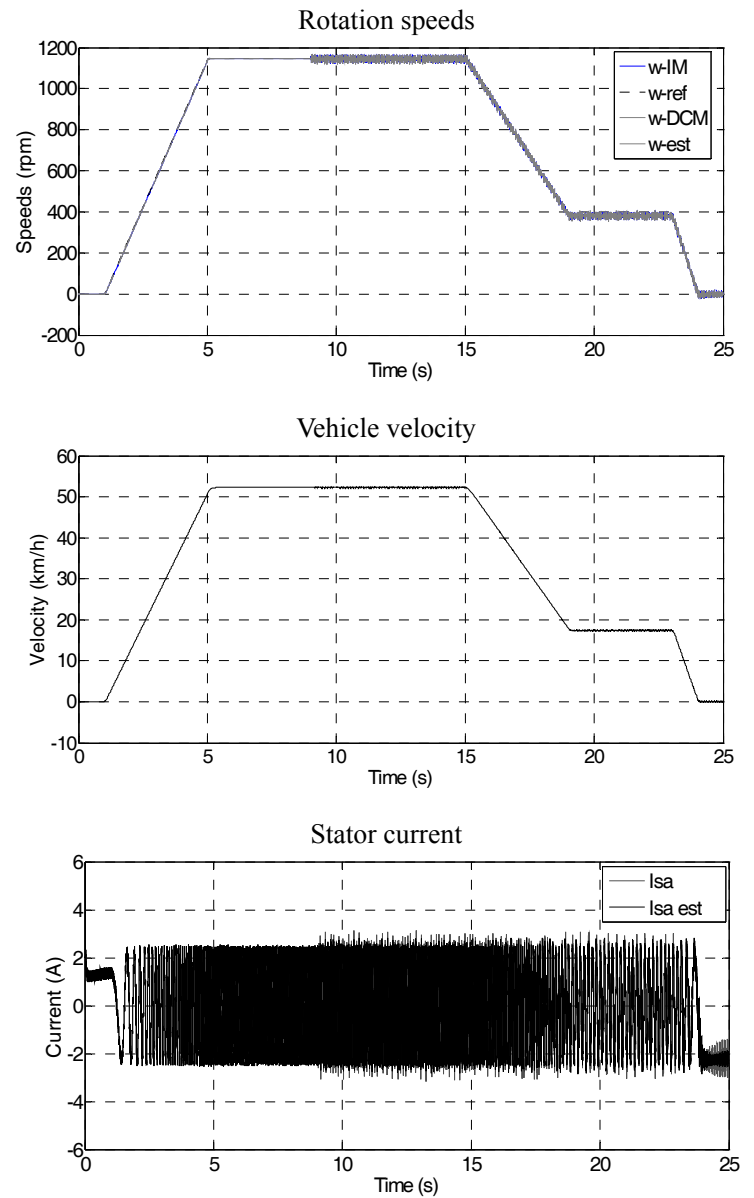

Fig.4. Two faults affect the motor in the stator and rotor 

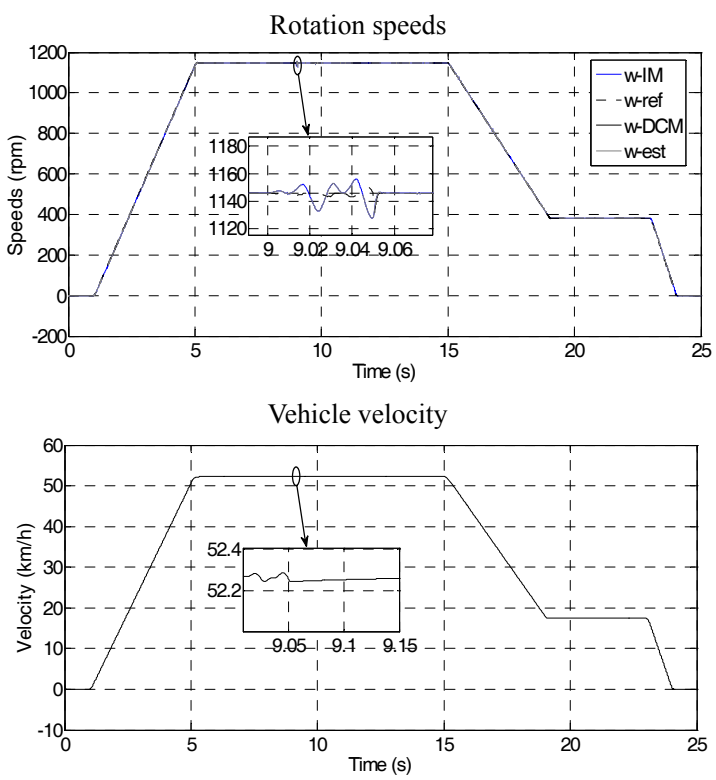

Stator current

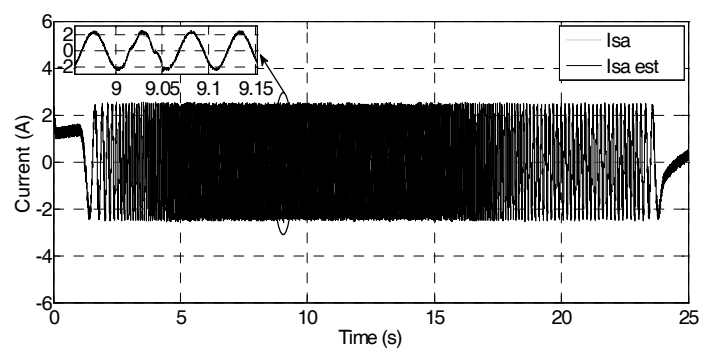

Fig. 5. One fault affects the motor in the stator with using the proposed FTC scheme

\subsection{Tests of the FTC approach}

The proposed fault-tolerant control strategy has been simulated on a $1 \mathrm{~kW}$ induction motor drive whose ratings are summarized in Appendix.

Then, two faults are introduced, one in the stator and the other in the rotor.

\section{Experimental Results}

\subsection{Test bench}

The test bench used to validate the proposed approach is illustrated in Fig. 7. It is made up of a $1-\mathrm{kW}$ induction motor drive whose ratings are given in the Appendix.

The experimental test-bench main components are a Static power electronics convertor from Semikron composed of a diode rectifier (AC-DC converter) and a three-leg voltage source IGBT inverter (DC-AC converter), current sensors of Hall, an optical encoder attached to the motor shaft, and a dSPACE 1104 development board, which is interfaced to a standard PC.

In this section experimental results are presented validating the proposed control on the experimental
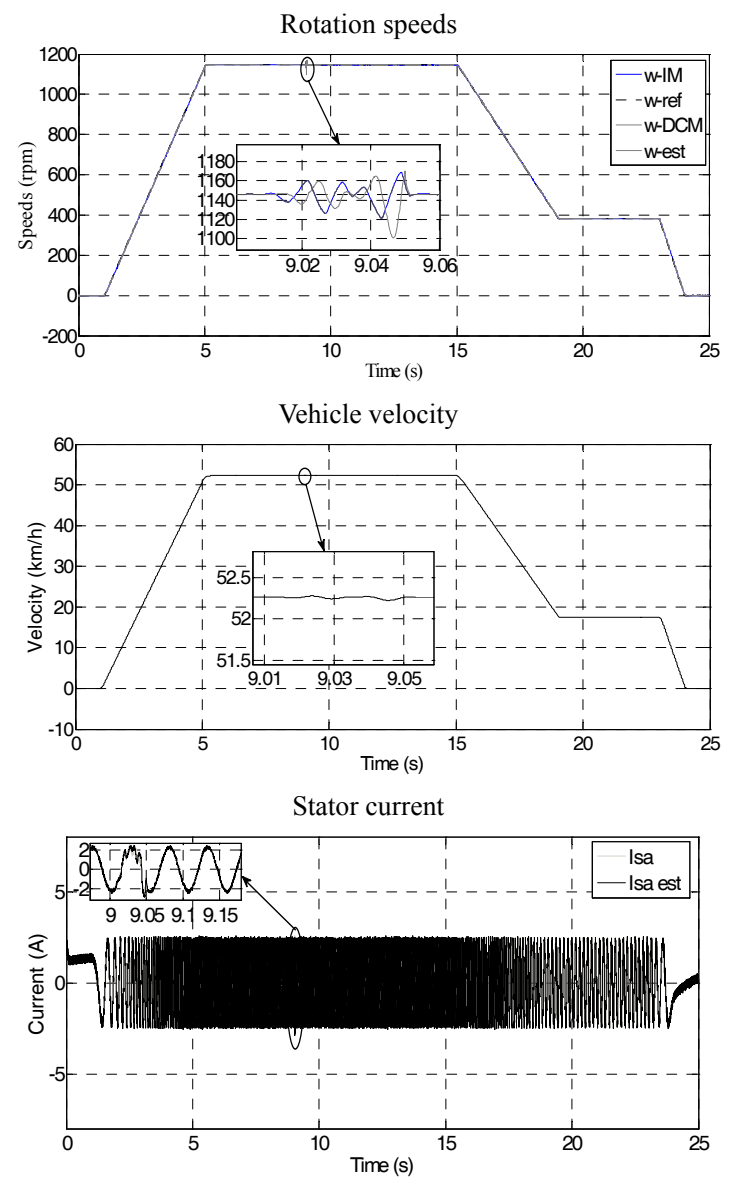

Fig. 6. Two faults affect the motor in the stator and rotor with using the proposed FTC scheme

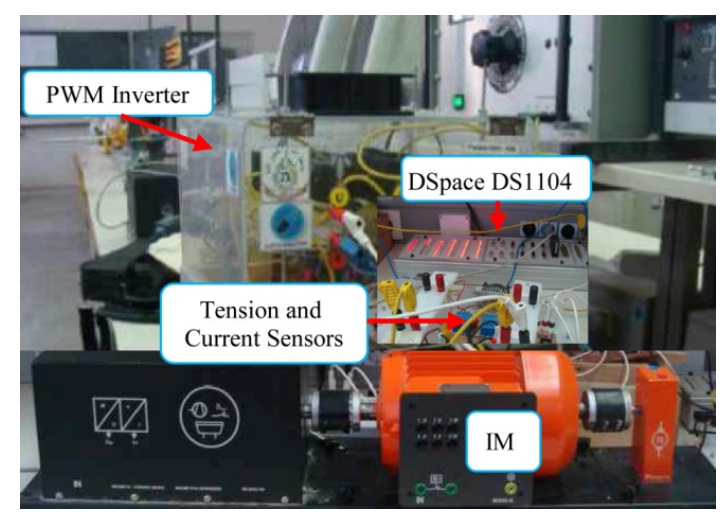

Fig. 7. Photograph of the experimental setup

viewpoint. To this purpose, a closed loop control system has been realized that is composed of the above IM, supplied by a voltage source inverter, The IM has been operated with a rotor flux of $1 \mathrm{~Wb}$. Both the controller and the observer have been implemented on a plat form involving a dSPACE1104 micro controller, operating under the Matlab/Simulink environment. The use of the dSPACE plat form is particularly important since it allows rapid prototyping of the control system and a real-time execution of it. 


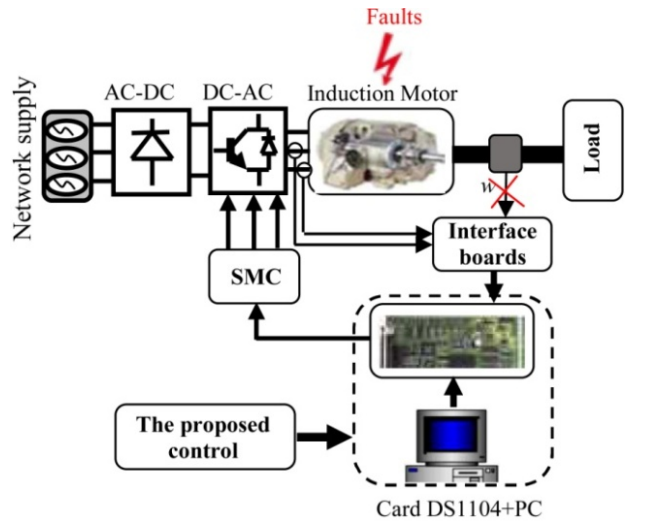

Fig. 8. Experimental test setup: schematic diagram
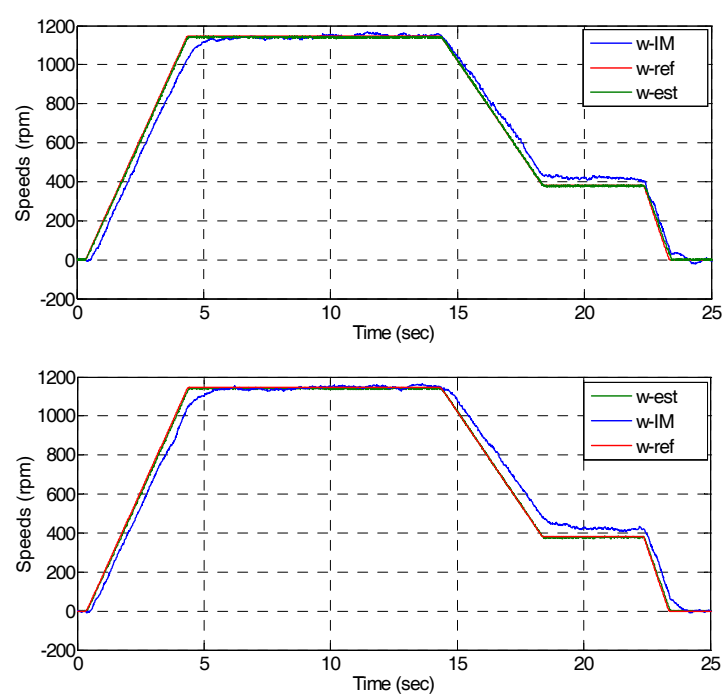

Fig. 9. Reference, real and estimated of IM speeds in faulty conditions (upper plot) in case of single fault affect the IM at time $\mathrm{t}=9 \mathrm{~s}$, and healthy conditions (lower plot) with using the proposed FTC scheme

The bloc diagram of the proposed fault tolerant controller used in the experimental set-up is presented in Fig. 8.

\subsection{Experimental tests}

The experimental results obtained are presented in Figs. (9-12) show clearly the effectiveness of the FTC scheme that occurs during the application of the fault by removing all defects thanks to the FTC strategy. In faulty conditions, it is found that the observer has better performance for high and low speeds. We see that the speed follow up the reference quickly and perfectly for the SMC which confirms the robustness of this technique.

\section{Conclusion}

This paper has presented a sensorless fault-tolerant
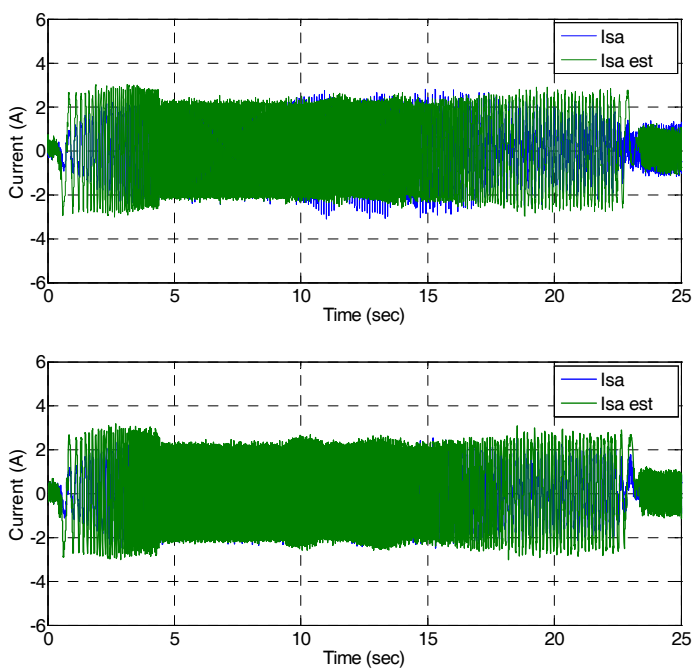

Fig. 10. Induction motor currents in faulty conditions (upper plot) in case of single fault affect the IM at time $\mathrm{t}=9 \mathrm{~s}$, and healthy conditions (lower plot) with using the proposed FTC scheme
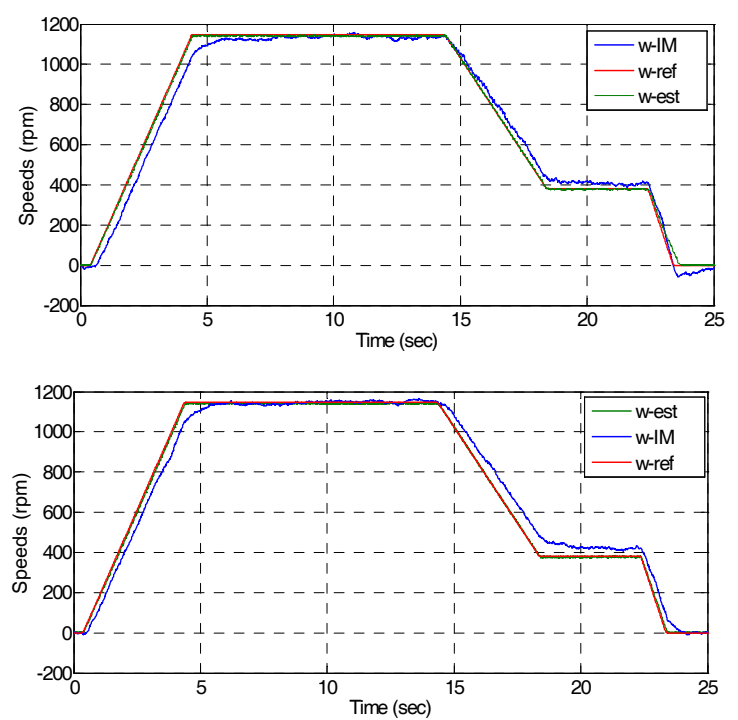

Fig. 11. Reference, real and estimated of IM speeds in faulty conditions (upper plot) in case of two faults affect the IM at time $\mathrm{t}=9 \mathrm{~s}$, and healthy conditions (lower plot) with using the proposed FTC scheme

sliding mode control strategy of induction motor based on electric vehicle application, suitable for dealing with electrical faults. A fault tolerant control based on SMC strategy is designed to steer the flux and the speed to their desired references in presence of rotor and stator resistance variations. The simulation and experimental results show the robustness of the proposed control scheme, and the results presented in this paper confirm that the EKF observer is more efficient. This controller presents high robustness in presence of the internal and the external perturbations. 

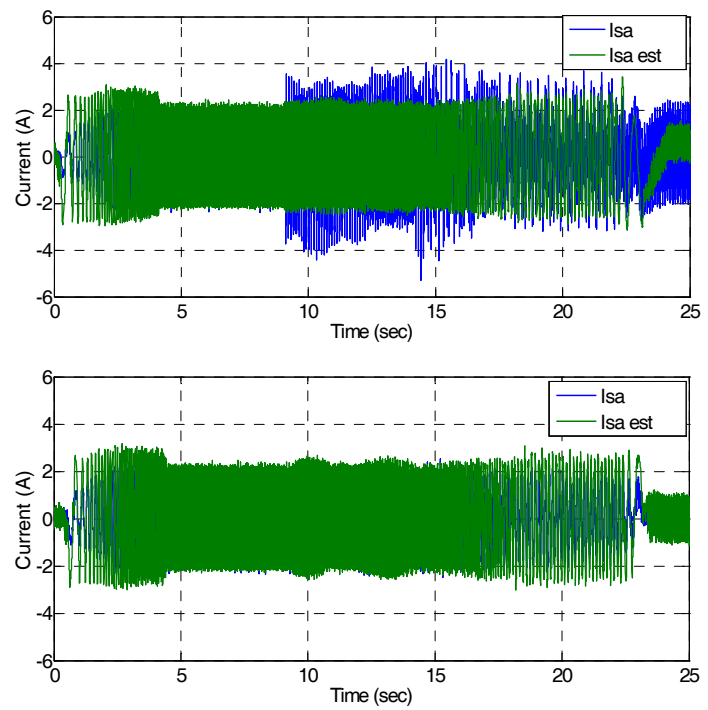

Fig. 12. Induction motor currents in faulty conditions (upper plot) in case of two faults affect the IM at time $\mathrm{t}=9 \mathrm{~s}$, and healthy conditions (lower plot) with using the proposed FTC scheme

\section{Appendix}

The Induction Motor parameters

$1 \mathrm{~kW}, 5 \mathrm{Nm}, 1400 \mathrm{rpm}, \mathrm{p}=2, \mathrm{Rs}=12.75 \Omega, R r=5.1498 \Omega$, $L s=0.4991 \mathrm{H}, \mathrm{Lr}=0.4331 \mathrm{H}, M=0.4331 \mathrm{H}, J=0.0035 \mathrm{~kg} . \mathrm{m}^{2}$

The DC Machine parameters

$1 \mathrm{~kW}, 5 \mathrm{Nm}, 1500 \mathrm{rpm}, \mathrm{Ra}=2.581 \Omega, R_{e}=281.3 \Omega, \mathrm{La}$ $=0.028 \mathrm{H}, L_{e}=156 \mathrm{H}, \mathrm{J}=0.02215 \mathrm{~kg} . \mathrm{m}^{2}$

\section{References}

[1] Gaeid, K.S.; Ping, H.W., "Fault tolerant control of induction motor", Mod. Appl. Sci. 2011, 5, 83-94.

[2] Cusidó, J.; Romeral, L.; Ortega, J.A.; Garcia, A.; Riba, J. "Signal injection as a fault detection technique". Sensors 2011, 11, 3356-3380.

[3] A. M. El-Refaie, "Fault-tolerant permanent magnet machines: A review". IET Power Appl., vol. 5, no. 1, pp. 59-74, Jan. 2011.

[4] D. U. Campos-Delgado, D. R. Espinoza-Trejo, and E. Palacios, "Fault-tolerant control in variable speed drives: A survey". IET Elect. Power Appl., vol. 2, no. 2, pp. 121-134, Mar. 2008.

[5] A. Sayed-Ahmed, B. Mirafzal, and N. A. O. Demerdash, "Fault-tolerant technique for $\Delta$-connected AC-motor drives" .IEEE Trans. Energy Convers, vol. 26, no. 2, pp. 646-653, Jun. 2011.

[6] K. Rothenhagen and F. W. Fuchs, "Current sensor fault detection, isolation, and reconfiguration for doubly fed induction generators". IEEE Trans. Ind. Electron., vol. 56, no. 10, pp. 4239-4245, Oct. 2009.

[7] D. U. Campos-Delgado, D. R. Espinoza-Trejo, and E. Palacios, "Fault tolerant control in variable speed drives: A survey". IET Elect. Power Appl., vol. 2, no. 2, pp. 121-134, Mar. 2008.

[8] M. E. H. Benbouzid, D. Diallo, and M. Zeraoulia, "Advanced fault tolerant control of induction-motor drives for $\mathrm{EV} / \mathrm{HEV}$ traction applications: From conventional to modern and intelligent control techniques”. IEEE Trans. Veh. Technol., vol. 56, no. 2, pp. 519-528, Mar. 2007.

[9] Ricardo de Castro, Rui Esteves Araújo, and Diamantino Freitas, "Wheel Slip Control of EVs Based on Sliding Mode Technique with Conditional Integrators". IEEE Transactions on Industrial Electronics, vol. 60, no. 8, August 2013.

[10] D. Yin, S. Oh, and Y. Hori, "A novel traction control for $\mathrm{EV}$ based on maximum transmissible torque estimation" IEEE Transactions on Industrial Electronics, vol. 56, no. 6, pp. 2086-2094, 2009.

[11] L. Chen, X. Sun, H. Jiang, and X. Xu, "A highperformance control method of constant $\mathrm{V} / f$-controlled induction motor drives for electric vehicles", Mathematical Problems in Engineering, vol.2014, Article ID386174, 10 pages, 2014.

[12] F. Alonge, F. D'Ippolito, A. Fagiolini, A. Sferlazza "Extended complex Kalman filter for sensorless control of an induction motor", Science direct, Control Engineering Practice 27 (2014), 1-10.

[13] I. Bakhti, S. Chaouch, A. Maakouf, T. Douadi "Robust sensorless non linear controls for induction motor with sliding mode observer", JCET Vol. 4 Iss. 2 April 2014 PP. 108-116.

[14] C. Bonivento et al., "Implicit fault-tolerant control: Application to induction motors", Science direct. Automatica, vol. 40, pp. 355-371, 2004.

[15] A. Bouscayrol, W. Lhomme, "Hardware-in-the-loop simulation of electric vehicle traction systems using Energetic Macroscopic Representation". IEEE IECON'06, Paris (USA), November 2006.

[16] Moura, S. J., Fathy, H. K., Callaway, D. S., Stein, J. L. "A stochastic optimal control approach for power management in plug-in hybrid electric vehicles". IEEE Trans. On Control Systems Technology 19(3), 545-554 (2011).

[17] T. Roubache, A. Kheloui, "Programmable emulator loading conditions of EV traction systems". JIEMCEM. Enset Oran-Algeria. May 25-26, 2010.

[18] A. Derdiyok, "A novel speed estimation algorithm for induction machines", Elect. Pow. Syst. Resr., no. 64, pp. 73-80, Jun. 2003.

[19] Harnefors L, Hinkkanen M, "Complete stability of reduced-order and full-order observers for sensorless IM drives", IEEE Trans. on Industrial Electronics 
2008; 55(3):1319-1329.

[20] M. Muenchhof et al., "Fault-tolerant actuators and drives - Structures, fault detection principles and applications", Annual Reviews in Control, October 2009.

[21] D.P. O'Leary, "Fast solvers and Sylvester equations: both sides now", Computing in Science \& Engineering, vol. $7, \mathrm{n}^{\circ} 6$, pp. 74-80, November-December 2005.

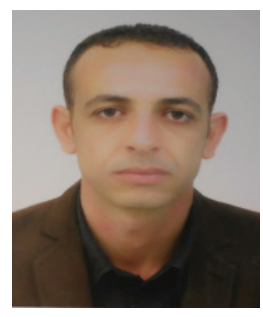

Toufik Roubache was born in M'sila, Algeria, in 1982. He received the B.Sc. degree from the University of M'sila, Algeria, in 2005, and the M.Sc. degrees from Military Polytechnic School, Algiers, Algeria, in 2008, all in Electrical Engineering. He is currently working toward the Ph.D. degree in Electrical Engineering at the University of Batna, Algeria. His research interests include the robust sensorless fault tolerant control of electrical drives.

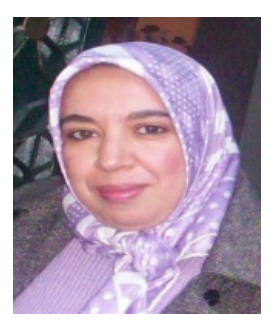

Souad Chaouch. was born in Batna, Algeria, in 1969. She received the B.Sc. degree in Electrical Engineering, from the University of Batna, Algeria, in 1993, and the M.Sc. degree in Electrical and automatic Engineering from the same university in 1998, She received her Ph.D. degree in 2005. She has been with the University of Msila, Algeria between 2000 and 2011. Now, she is an Associate Professor in the Electrical Engineering Department at the University of Batna. She is a member in the Research Laboratory of Electr omagnetic Induction and Propulsion Systems of Batna University. Her scientific research includes electric machines and drives, automatic controls, Sensorless and Nonlinear controls.

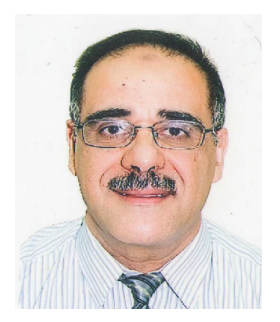

Mohamed-Saïd Naït-Saïd was born in Batna, Algeria, in 1958. He received the Engineer Diploma in Electrical Engineering from the National Polytechnic High School of Algiers, Algeria in February 1983, and the MSc degree in Electronics and Control Engineering from Electronics department of Constantine University in 1992. He received the Phd degree in Electrical Engineering from University of Batna after its free scientific researches accomplished in Automatic Laboratory of Amiens University in French from 1996 to 1999. Currently he is a full professor at the Electrical
Engineering Department of Batna University II and assures the chief of the Master course of Control and Diagnosis of the Electrical Systems. From 2000-2005, Dr. Naït-Saïd was the head of the first created research laboratory in Batna University, named Electromagnetic Induction and Propulsion Systems (LSPIE) of Batna and also in 2006 the head of scientific committee of the same department. LSPIE has been evaluated by the Algerian ministry of the universities as the best laboratory in Batna University (100 percent satisfactory). Dr. Naït-Saïd has supervised twenty five Masters and ten Phd thesis. His research interests include the electric machines and their control drives and diagnosis. 